\title{
Образ идеального ученого у современной российской молодежи
}

\author{
Татьяна В. Разина', Елена А. Володарская ${ }^{2 *}$ \\ ${ }^{1}$ Российская академия образования, г. Москва, Российская Федерация \\ 2 Институт истории естествознания и техники им. С. И. Вавилова РАН, г. Москва, \\ Российская Федерация \\ *E-mail: eavolod@gmail.com
}

\begin{abstract}
Аннотация
Ввеление. Авторами Аоказывается актуальность изучения образа илеального ученого у современных молодых россиян Аля понимания формирования их профрессиональных предпочтений и желания заниматься научной деятельностью в современных условиях функционирования науки. Новизна исследования зак^ючается в установлении структурно-содержательного своеобразия имиАжа ученого у студентов и работающей молоАежи, и фракторов, его обуславАивающих. Материалы и метоАы. В разАеле описываются поАготовительный и основной этапы исследования, которые включали в себя методы семантического дифрференциала, ^абораторного эксперимента, фракторного анализа.

Результаты. Основной этап исслеАования позволил смоделировать семантическое пространство, отражающее характеристики образов илеального ученого и размичных кинематографических образов ученых в сознании студентов и работающей молодежи. Образ идеального ученого характеризуется когнитивными (способность фрормулировать проблему, выражать свои мысли, устойчивость к неопрелеленности, Аисциплина мышления) и личностными (целеустремленность, решительность, принципиальность, нацеленность на результат, высокая работоспособность, разносторонность, неординарность, богатая орантазия) качествами.
\end{abstract}

ОбсужАение результатов. Авторы показывают, что студенты, А^я которых усвоение научных знаний выступает основой образовательной Аеятельности, конструируют образ ученого с опорой на свои знания о реальных научных работниках и на преАставления о научной Аеятельности как о мыслительной, интеллектуальной работе, что отражается в оценке кинематографических образов. Работающая мололежь, в силу отсутствия научного поиска в содержании профрессиональной Аеятельности, отАаленности от актуального положения Ае^ в науке, испытывает Аефицит объективной инорормации и конструирует образ ученого на своих прошлых преАставлениях о научных работниках, а также кинематографических образах, отражающих стереотипные представления об ученых (чаще через демонстрацию средств научного труда). Это говорит об упрощении образа ученого у работающей мололежи. 
В заключение Аелается вывоА о содержательной схожести образов илеального ученого у работающей и учащейся мололежи, и отличиях в его имиАжфоормирующей основе.

\section{КАючевые слова}

илеальный ученый, имиАж, имиАжформирующая основа, кинематографический образ, когнитивный фрактор, мичностный фрактор, образ ученого, профрессиональная Аеятельность, стереотип, учебная Аеятельность

\section{Основные положения}

- у современной мололежи образ ученого может быть описан посредством Авух фракторов (когнитивного и личностного), и является Аостаточно упрощенным; - имилжфоормирующей основой образа ученого у мололежи выступают Аеятельность (профрессиональная или учебная) и кинематографические образы;

- образ илеального ученого базируется на знаниях мололежи о реальных научных работниках и стереотипах, транслируемых в кинематографических образах.

\section{Благодарности}

Авторы выражают благодарность за помощь в сборе эмпирических данных бакалавру психологии М. Д. Рогозиной.

\section{Для цитирования}

Разина Т.В., Володарская Е.А. Образ идеального ученого у современной российской молодежи // Российский психологический журнал. - 2017. - Т. 14, № 4. - С. 8-25.

Материалы статьи получены 07.08.2017 


\title{
The Image of an Ideal Scientist Among Modern Russian Youth
}

\author{
Tat'yana V. Razina', Elena A. Volodarskaya ${ }^{2 *}$ \\ ${ }^{1}$ Russian Academy of Education, Moscow, Russian Federation \\ ${ }^{2}$ S. I. Vavilov Institute for the History of Science and Technology RAS, Moscow, Russian \\ Federation \\ * Correspondence author. E-mail: eavolod@gmail.com
}

\begin{abstract}
Introduction. Studying the image of an ideal scientist among modern young Russians is important for understanding their professional preferences and desire to engage in scientific activities in modern conditions of science. The research concentrates on structural and substantial characteristics of the image of a scientist among students and working young people, and also their factors.
\end{abstract}

Materials and Methods. The stages of the research included methods of semantic differential, laboratory experiment, and factor analysis.

Results. The main stage of the research made it possible to construct the semantic space reflecting the characteristics of the images of an ideal scientist and various cinematographic images of scientists among students and working young people. The image of an ideal scientist had cognitive (ability to formulate problems and express ideas, tolerance for uncertainty, and the discipline of thinking) and personal (purposefulness, resoluteness, adherence to principle, focus on results, high working capacity, versatility, originality, rich imagination) qualities.

Discussion. The students for whom the assimilation of scientific knowledge is the basis for educational activities construct the image of a scientist being guided by their knowledge about real scientists and the idea about scientific activity as a thinking and intellectual work. Assessing cinematographic images reflects this. Working young people have a lack of scientific research in the content of professional activity; they are estranged from scientific reality and suffer from a lack of objective information. Thus, working young people construct the image of a scientist on the basis of their representations about scientists and also cinematographic images, reflecting stereotypes of scientists (often through demonstrating the tools of scientific work). This testifies to the simplification of the image of a scientist among working young people.

Substantial characteristics of the image of an ideal scientist are analogous among working and studying young people. However, the image forming foundation differs in the two studied groups. 


\section{Keywords}

ideal scientist, image, image creating basis, cinematographic image, cognitive factor, personal factor, image of scientist, professional activity, stereotype, educational activity

\section{Highlights}

- Two factors (cognitive and personal) describe the image of a scientist among modern young people; it is rather simplified.

- Professional or learning activity and cinematographic images form the image creating basis for the image of a scientist among young people.

- Young people's knowledge about real scientists and stereotypical cinematographic images influence the image of an ideal scientist.

\section{Acknowledgments}

The authors express appreciation of M. D. Rogozina's assistance in gathering empirical data.

\section{For citation}

Razina T.V., Volodarskaya E. A. The Image of an Ideal Scientist Among Modern Russian Youth. Rossiiskii psikhologicheskii zhurnal - Russian Psychological Journal, 2017, V. 14, no. 4, pp. 8-25 (in Russian).

Original manuscript received 07.08.2017

\section{Введение}

Социально-психологическое изучение механизмов восприятия науки и формирования представлений о ней, исследование системы отношений науки и общества стали предметом целенаправленного самостоятельного анализа феноменологии имиджа науки. Значимыми дискуссионными вопросами являются вопросы социально-психологической детерминации формирования этого феномена, методологии его анализа, принципов функционирования, психологических возможностей целенаправленного управления, содержательной специфики имиджа науки у разных социальных групп, его влияния на профессиональные предпочтения, в частности, молодежи, на интерес и научное мировоззрение, а также многие другие аспекты проблемного поля имиджа науки.

Субъект научного творчества - ученый, научные группы, наука в целом, представления о ней, существующие в обществе, могут быть проанализированы в трехмерном пространстве предметного, социального и психологического векторов. 
Динамика имиджа науки может быть связана с непрерывным ускорением развития научной мысли, быстрым расширением объема научного знания, изменениями социального контекста функционирования института науки, усложнением форм взаимодействия науки и общества, а также спецификой практического запроса, который выступает важным драйвером теоретического осмысления социально-психологических проблем в целом.

Основными информационными каналами формирования социальных представлений о науке выступают непосредственное взаимодействие с представителями профессионального научного сообщества, собственный опыт исследовательской деятельности (непосредственная имиджформирующая основа), а также деятельность СМИ, слухи, влияние третьих лиц (опосредованная имиджформирующая основа).

Транслируемая в СМИ информация о деятельности ученых, состоянии научного сообщества приводит к формированию образа данной сферы социальной практики у молодых поколений, опосредуя профессиональные предпочтения и выбор возможной самореализации в исследовательской деятельности.

В ходе нашего исследования мы предполагали, что, во-первых, характер деятельности личности (учебно-профессиональная у студентов и трудовая у работающей молодежи) определяет представления о науке и научных работниках, обеспечивая существенные отличия в данных представлениях.

Во-вторых, имидж ученого у современной молодежи в значительной степени взаимосвязан с транслируемыми СМИ (в частности, кинематографом) образами научных работников.

Целью данной статьи является изучение содержательных характеристик имиджа ученого у различных групп современной молодежи, а также взаимосвязь этих характеристик с образами научных работников, формируемых кинематографом. Объектом исследования выступил образ идеального ученого.

Предметом исследования стало сравнение кинематографических образов ученого и образа идеального ученого у молодых людей в их структурносодержательных имиджевых характеристиках.

\section{Теоретические основы исследования}

Специфика имиджа науки рассматривается с опорой на общепсихологические [1] и социально-психологические подходы в исследовании научной деятельности и творческого мышления [2, 3, 4, 5, 6], исследование индивидуально-психологических особенностей ученого и коллективного характера исследовательской деятельности $[7,8,9,10,11]$, принципы имиджелогического 
подхода к анализу конкретных субъектов имиджа $[12,13,14,15]$, теорию социальных представлений [16].

\section{Материалы и методы}

Выборка включала в себя 77 испытуемых - жителей г. Ярославля. Первую группу (учащиеся) составили 42 студента старших курсов психологического и математического факультетов, из них девушек - 35 (83,3\%), юношей - 7 (16,7\%). Средний возраст - 22,7 года. Во вторую группу испытуемых (работающие) вошли 35 сотрудников коммерческой организации, работающих в сфере IT, из них девушек - 21 (60\%), юношей - 14 (40\%). Средний возраст - 26,7 лет, 91 \% респондентов этой группы имеют высшее образование.

Критерием выделения групп респондентов стали опыт использования научного знания и вовлеченность в научную среду разными аудиториями имиджа науки. Взаимодействие студентов со сферой науки проявляется в усвоении научного знания в ходе реализации программ учебных дисциплин по соответствующим образовательным стандартам, непосредственного общения с преподавателями, формирования навыков самостоятельной исследовательской деятельности. У респондентов, работающих в сфере IT, личный научный опыт, полученный ранее в вузе, расширяется за счет применения навыков в профессиональной деятельности при работе с программными продуктами и высокими технологиями.

Исследование осуществлялось в два этапа.

Первый этап (подготовительный) был направлен на выделение содержательной специфики образа ученого у респондентов. Для этого был использован метод семантического дифференциала, в ходе которого респонденты должны были оценить идеального, по их мнению, ученого по 31 биполярной шкале с семибалльной градацией от -3 до +3. Шкалы включали личностные, профессиональные качества, которые могут характеризовать научных работников. Выбор данного набора шкал обусловлен результатами предыдущих исследований, в частности, данными контент-анализа мнений заведующих кафедрами и руководителями исследовательских лабораторий по поводу оценки исследовательской продуктивности характеристик их непосредственных подчиненных-ученых [17]. Были выделены такие качества ученого, как ум, целеустремленность, решительность, принципиальность, честность, разносторонность, неординарность, самокритичность, высокая работоспособность, добросовестность, известность, высокая самооценка, нацеленность на результат, любознательность, настойчивость, воображение, гибкость ума, терпимость, чувство юмора, оптимизм, умение выражать свои мысли, умение принимать новое, готовность рисковать, независимость мышления, 
ОБЩАЯ ПСИХОЛОГИЯ

образность мышления, терпимость к неопределенности, самодисциплина, нравственность, оригинальность, инициативность и др.

Полученный массив данных был подвергнут факторному анализу (варимакс нормализованный). Метод каменистой осыпи показал наличие двух факторов, в которые вошли шкалы, имевшие факторный вес более 0,7 (таблица 1).

Таблица 1. Распрелеление шкал на фракторы в результате фракторного анализа

Table 1. Distribution of scales by factors after factor analysis

\begin{tabular}{|c|c|c|}
\hline $\begin{array}{c}\text { Шкалы семантического } \\
\text { Аифференциала } \\
\text { Scales of semantic differential }\end{array}$ & $\begin{array}{c}\text { Фактор } 1 \text { мичностный } \\
\text { Factor } 1 \text { personal }\end{array}$ & $\begin{array}{l}\text { Фактор } 2 \text { когнитивный } \\
\text { Factor } 2 \text { cognitive }\end{array}$ \\
\hline $\begin{array}{l}\text { Целеустремленность } \\
\text { Purposefulness }\end{array}$ & 0,81 & 0,22 \\
\hline $\begin{array}{l}\text { Решительность } \\
\text { Resoluteness }\end{array}$ & 0,77 & 0,15 \\
\hline $\begin{array}{l}\text { Принципиальность } \\
\text { Adherence to principle }\end{array}$ & 0,71 & 0,26 \\
\hline $\begin{array}{l}\text { Разносторонность } \\
\text { Versatility }\end{array}$ & 0,70 & 0,31 \\
\hline $\begin{array}{l}\text { НеорАинарность } \\
\text { Originality }\end{array}$ & 0,75 & 0,17 \\
\hline $\begin{array}{l}\text { Высокая работоспособность } \\
\text { High working capacity }\end{array}$ & 0,72 & 0,33 \\
\hline $\begin{array}{l}\text { Нацеленность на результат } \\
\text { Focus on results }\end{array}$ & 0,76 & 0,23 \\
\hline $\begin{array}{l}\text { Фантазия } \\
\text { Rich imagination }\end{array}$ & 0,75 & 0,14 \\
\hline $\begin{array}{l}\text { Способность правильно } \\
\text { срормулировать проблему } \\
\text { Ability to formulate problems } \\
\text { properly }\end{array}$ & 0,15 & 0,72 \\
\hline $\begin{array}{l}\text { Терпимость } \\
\text { к неопределенности } \\
\text { Tolerance for uncertainty }\end{array}$ & 0,19 & 0,71 \\
\hline $\begin{array}{l}\text { Аисциплина } \\
\text { Discipline }\end{array}$ & $-0,03$ & 0,74 \\
\hline $\begin{array}{l}\text { Собственное значение } \\
\text { Own value }\end{array}$ & 8,56 & 6,17 \\
\hline $\begin{array}{l}\text { Аоля Аисперсии } \\
\text { Dispersion proportion }\end{array}$ & 0,28 & 0,20 \\
\hline
\end{tabular}


На основании того, какие шкалы вошли в тот или иной фактор, они были условно обозначены как «личностный» и «когнитивный». Личностный фактор включал индивидуально-психологические, характерологические качества человека, которыми, по мнению респондентов, должен обладать ученый. Когнитивный фактор включал качества, необходимые для эффективной интеллектуальной работы ученого в процессе исследовательской деятельности.

Отметим, что выделенные факторы в сумме исчерпывают лишь $45 \%$ дисперсии, что говорит о наличии неких иных, латентных качеств, важных для характеристики ученых, но не вошедших в факторы. Это может быть следствием крайне различных представлений об ученых, бытующих в группе респондентов, а также говорить об отсутствии однозначно и четко определенного образа представителя данной сферы деятельности. Последнее подтверждается отзывами самих испытуемых, которые при выполнении задания отмечали, что они не знают, как к нему приступить, затрудняются в оценке качеств идеального ученого, никогда не задумывались над этим вопросом.

Bmoрой этаn (основной) исследования был направлен на изучение имиджа идеального ученого, а также оценку образов научных работников - героев 12-ти кинолент с последующим сравнением меры схожести представлений об ученом, сложившихся у молодых людей, с кинематографическими образами, транслируемыми в СМИ, и построением семантического пространства.

Исследование представляло собой по форме лабораторный эксперимент, в ходе которого респондентам показывались видеозаписи одно- и двухминутных фрагментов из 12-ти фильмов, где главными героями были ученые. Экспериментальный материал был подобран таким образом, чтобы в нем присутствовали фильмы как автобиографического характера, так и фантастика, во-первых, с вымышленным (например, оживление искусственного человека, создание машины времени, посещение марсиан и т. д.) и, во-вторых, с реалистичным (чтение лекции, лабораторные исследования и т. д.) сюжетами демонстрируемых фрагментов художественных фильмов.

Испытуемые должны были оценить сначала идеального, по их мнению, современного ученого, а затем отдельно каждый образ из показанных в видеофрагментах ученых. Оценка производилась на основе 11-ти шкал, полученных на первом этапе исследования. Результаты обрабатывались с помощью методов описательной статистики и формул для подсчета семантических расстояний в двухфакторном семантическом пространстве.

\section{Результаты}

Семантическое пространство имиджа идеального ученого и оценок кинематографических образов научных работников в обеих группах студентов и работающих респондентов представлено на рисунке 1. 


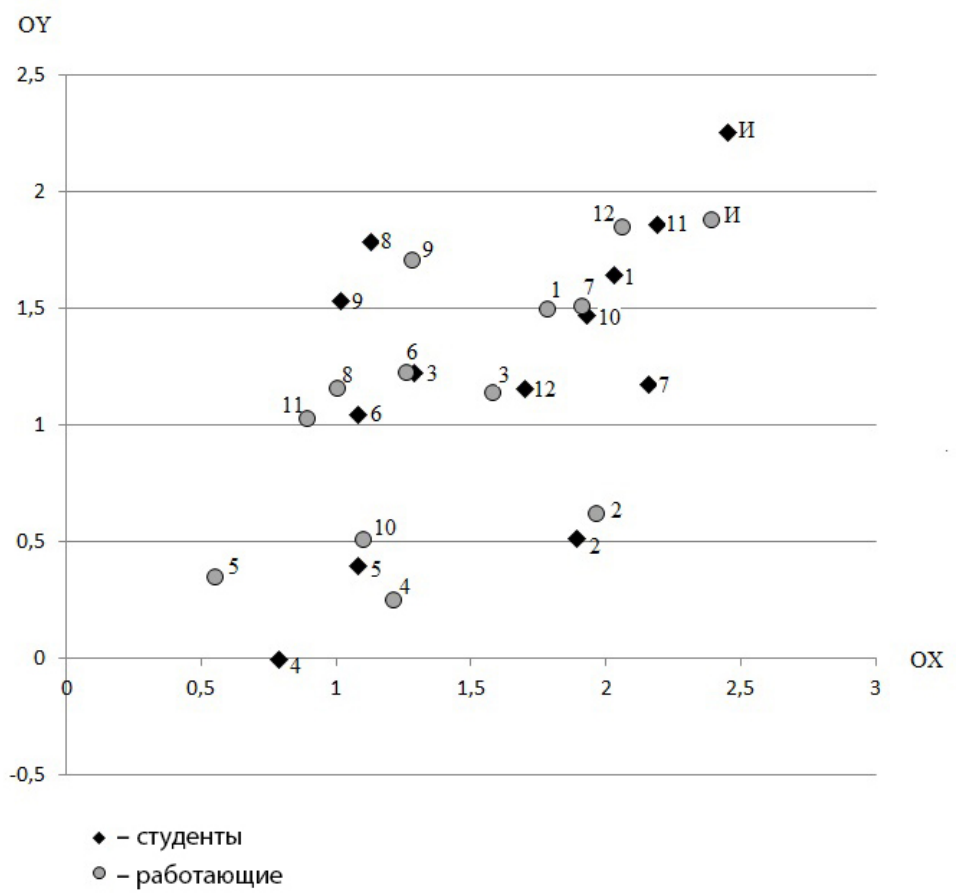

Рисунок 1. Семантическое пространство образов ученого в группах студентов (№ 1) и работающей молодежи (№ 2)

Figure 1. Semantic space of the image of a scientist in the group of students (no. 1) and the group of working young people (no. 2)

Условные обозначения: ОХ - личностный фактор, ОY - когнитивный фактор. Точки семантического пространства: И - идеальный образ, под номерами - кинематографические образы ученых из фильмов: 1 - «Академик Иван Павлов», реж. Г. Л. Рошаль, («Мосфильм», 1949); 2 - «Назад в будущее», реж. Р. Земекис ("Universal», 1985); 3 - «Парк юрского периода», реж. C. Cпилберг ("Universal», 1993); 4 - «Ван Хельсинг», реж. С. Соммерс («Central Partnership», 2004); 5 - «Охотники за привидениями», реж. А. Райтман («MGM», 1984); 6 - «Красные огни», реж. P. Кортес («Warner Bros.», 2011); 7 - «Чокнутый профессор», реж. Т. Шэдьяк («Universal», 1996); 8 - «Марс атакует», реж. Т. Бёртон («Warner Bros.», 1996); 9 - «Прибытие», реж. Д. Вильнёв («Ранатount», 2016); 10 - «Вселенная Стивена Хокинга», реж. Д. Марш («Working Title Films», 2014); 11 - «Игры разума», реж. Р. Ховард («DreamWorks SKG», 2001); 12 - «Невероятный Халк», реж. Л. Летерье («Marvel Enterprises», 2008).

Было подсчитано семантическое расстояние в группах студентов и работающей молодежи между оценкой идеального ученого и оценкой ученых, созданных кинематографом (таблица 2). 
Таблица 2. Семантические расстояния межАу образом илеального ученого и кинематограффическими образами в Авух группах

Table 2. Semantic distance between the image of an ideal scientist and cinematographic images in two groups

\begin{tabular}{|c|c|c|c|}
\hline & $\begin{array}{l}\text { Название фильма } \\
\text { Movie title }\end{array}$ & $\begin{array}{l}1 \text { группа } \\
\text { Group no. } 1\end{array}$ & $\begin{array}{l}2 \text { группа } \\
\text { Group no. } 2\end{array}$ \\
\hline 1. & $\begin{array}{l}\text { "Акалемик Иван Пав^ов" } \\
\text { "Academician Ivan Pavlov" }\end{array}$ & 0,74 & 0,72 \\
\hline 2. & $\begin{array}{l}\text { «Назад в будущее»" } \\
\text { "Back to the Future" }\end{array}$ & 1,83 & 1,33 \\
\hline 3. & $\begin{array}{l}\text { «Парк юрского периода» } \\
\text { "Jurassic Park" }\end{array}$ & 1,55 & 1,10 \\
\hline 4. & \begin{tabular}{|l} 
"Baн Хемьсинг»" \\
"Van Helsing"
\end{tabular} & 2,80 & 2,01 \\
\hline 5. & $\begin{array}{l}\text { "Охотники за привидениями» } \\
\text { "Ghostbusters" }\end{array}$ & 2,31 & 2,39 \\
\hline 6. & $\begin{array}{l}\text { "Красные огни» } \\
\text { "Red Lights" }\end{array}$ & 1,83 & 1,30 \\
\hline 7. & $\begin{array}{l}\text { «Чокнутый профеecсор» } \\
\text { "The Nutty Professor" }\end{array}$ & 1,12 & 0,61 \\
\hline 8. & $\begin{array}{l}\text { "Mapc aтакует» } \\
\text { "Mars Attacks" }\end{array}$ & 1,40 & 1,57 \\
\hline 9. & $\begin{array}{l}\text { «Прибытие» } \\
\text { "The Arrival" }\end{array}$ & 1,60 & 1,12 \\
\hline 10. & $\begin{array}{l}\text { "Вселенная Стивена Хокинга» } \\
\text { "The Universe with Stephen } \\
\text { Hawking" }\end{array}$ & 0,94 & 1,88 \\
\hline 11. & $\begin{array}{l}\text { «Игры разума»" } \\
\text { "A Beautiful Mind" }\end{array}$ & 0,47 & 1,72 \\
\hline 12. & $\begin{array}{l}\text { «Невероятный Ха^к»" } \\
\text { "The Incredible Hulk" }\end{array}$ & 1,33 & 0,33 \\
\hline & $\begin{array}{l}\text { Cpe } \Delta \text { Hee } \\
\text { Mean score }\end{array}$ & 1,49 & 1,34 \\
\hline & $\begin{array}{l}\text { Стандартное отклонение } \\
\text { Standard deviation }\end{array}$ & 0,66 & 0,61 \\
\hline
\end{tabular}

Примечание: «жирным» шрифтом выделены минимальные расстояния между кинематографическим образом и образом идеального ученого, курсивом - максимальные расстояния.

Note: bold font indicates the minimum distance between the cinematographic image and the image of an ideal scientist; italic font indicates the maximum distance. 


\section{Обсуждение результатов}

В обеих группах объект «идеальный ученый» характеризовался максимальными баллами по личностному и когнитивному факторам и, таким образом, в семантическом пространстве располагался в правом верхнем углу (рисунок 1). Если ориентироваться на содержание шкал, вошедших в личностный и когнитивный факторы, то идеальный ученый должен обладать такими качествами, как целеустремленность, решительность, принципиальность, нацеленность на результат. По-видимому, это должно обеспечиваться за счет высокой работоспособности, которую респонденты также приписывают ученым. Кроме того, научный работник воспринимается как разносторонне развитая и неординарная личность, обладающая богатой фантазией.

Набор когнитивных качеств идеального ученого включает способность правильно формулировать проблему, выражать свои мысли, что бесспорно является крайне важным в научной работе. Помимо этого, ученый должен обладать устойчивостью к неопределенности, т. е. действовать, работать в ситуации, когда вопросов больше, чем ответов. Эта характеристика достаточно близка к конструкту когнитивной незавершенности, который сейчас активно исследуется в контексте развития интеллектуального творчества $[18,19]$. Другой важной характеристикой является внутренняя дисциплина, в том числе и дисциплина мышления.

Показательно, что ни в один фактор не вошла такая характеристика, как ум. Вероятно, это связано с тем, что высокий ум оценивался респондентами как качество, которое присуще не только ученым. Также образ ученого по данному критерию мог быть оценен двояко: с точки зрения сложности решаемых научных проблем и с точки зрения стереотипа о поведении ученого в реальной жизни как «недотепы», «не от мира сего», беспомощного, неадаптивного (т. е. неумного). Подобное двоякое восприятие идеального ученого определяется разными аспектами имиджа. Предметный компонент имиджа науки связан с оценкой содержания предметной деятельности, развитием знания о природе и обществе. Поиск нового обуславливает возможность ухода исследователя от повседневных проблем. Это, в свою очередь, влияет на оценку социального аспекта имиджа науки, положение ученого в обществе, статус и престиж профессии. В этой связи характеристика «ум» может быть встроена в континуум «теоретический - практический», что и проявилось в противоречии этих двух типов и в отсутствии признака ума в имидже идеального ученого.

Семантическое расстояние между образами идеальных ученых в двух группах составило 0,37 и попадает в зону средних значений (среднее 0,57, стандартное отклонение 0,41). Таким образом, можно сказать, что представления об идеальном ученом в группе студентов и в группе работающей 


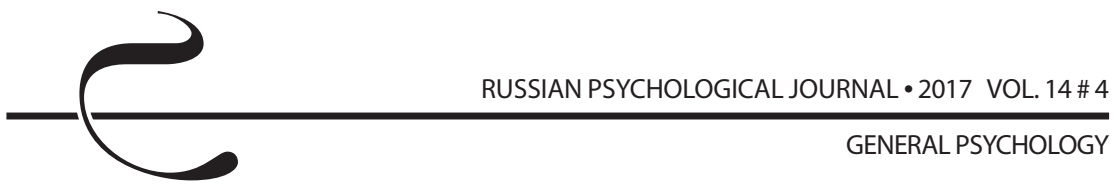

молодежи не имеют кардинальных отличий, хотя, безусловно, не идентичны. Основой для этих сходных представлений является, по-видимому, опыт получения высшего образования, который уже состоялся у большинства работающих респондентов и на момент исследования был актуальным для группы студентов.

На рисунке 1 в семантических пространствах двух групп испытуемых видно, что ученые - художественные герои оценены более низко по обоим факторам по сравнению с оценками идеального ученого. При этом, вероятно, кинематографические образы ученых, более близких в оценках к образу идеального ученого, послужили прототипами, имиджформирующей основой для создания образа идеального ученого или отражают некоторые черты этого образа.

Данные в таблице 2 показывают, что для студентов наиболее близкими к образу идеального ученого оказались видеосюжеты, описывающие жизнь реальных ученых - Ивана Петровича Павлова, Алана Тьюинга, Стивена Хокинга. Фрагменты фильмов об этих людях демонстрировали беседы ученого с друзьями и коллегами в привычных ситуациях, размышления, логические рассуждения, т. е. интеллектуальную, мыслительную деятельность.

В группе работающих молодых людей наиболее близкими к образу идеального ученого стали образы как реальных ученых (И. П. Павлов), так и вымышленные персонажи (биохимики из фантастических фильмов «Чокнутый профессор» и «Невероятный Халк»). Все видеосюжеты демонстрировали вполне реалистичные ситуации исследовательской деятельности - работу ученого в лаборатории, но получаемый продукт был фантастический. В сюжете про И. П. Павлова лабораторное оборудование имеет подчиненное значение по сравнению с содержанием диалогов, но все равно присутствует. В сюжетах про биохимиков лабораторное оборудование, работа с ним и созданное в результате вещество-продукт выходят на первый план, составляют их основное содержание при отсутствии рассуждений героя, которые могли бы свидетельствовать об интеллектуальных усилиях. Вероятно, для испытуемых второй группы важным критерием формирования представлений об идеальном ученом выступает наличие инструментов и продуктов труда ученого, иными словами, средового имиджа. Это согласуется с нашими исследованиями образа ученого в рисунках детей, где в качестве основного критерия, определяющего принадлежность к научному миру, выступает наличие лабораторного оборудования, в первую очередь, разнообразных пробирок для химических опытов [20].

Общим для обеих групп испытуемых стал фрагмент фильма про И. П. Павлова, когда главный герой оценен всеми респондентами как наиболее близкий к образу идеального ученого. Возможное это следствие 
известности выдающегося русского ученого-физиолога подавляющему числу молодых людей, принявших участие в исследовании. Фактор знания о реальных ученых и их вкладе в науку, по-видимому, является определяющим для формирования образа научного работника. В то же время, когда таких знаний нет, в качестве наполнения образа начинают выступать внешние средовые критерии - инструменты и материальные продукты научного труда.

Не менее интересным является анализ кинематографических образов, которые, по мнению испытуемых, в наименьшей степени соответствуют образу идеального ученого. В группе студентов и в группе работающих выявились одни и те же образы, а именно: образ ученого-злодея, создавшего Франкенштейна из фильма «Ван Хельсинг», и образ психолога из фильма «Охотники за привидениями». Респонденты достаточно однозначно квалифицировали эти фильмы как фантастические, а соответственно, действующие там ученые, их методы работы, инструменты и продукты вымышлены, далеки от реальности. Более того, в фильме «Ван Хельсинг» ученый обладает крайне непривлекательной, отталкивающей внешностью, является «злым гением». Несмотря на то, что характеристики «красота» и «гуманизм», как имиджформирующие качества ученого, не вошли в основные (когнитивный и личностный) факторы образа исследователя, они, по-видимому, все-таки могли оказать влияние на выбор респондентов на основе принципа системносмысловой организации перцептивного образа при присутствии некоторой центральной характеристики. Красивого ученого из фильмов респонденты оценили как хорошего, честного, умного и талантливого, а уродливого героя - как плохого, лживого, глупого, злого.

В фильме «Охотники за приведениями» ученый выглядит симпатичным, но по своему амплуа приближается скорее к «неудачнику» или «простаку», что также не вяжется с положительным образом. Для первой группы значимым был факт демонстрации проведения психологического эксперимента по выявлению паранормальных способностей. Изучение этих явлений не входит в предметное поле современной научной психологии и могло показаться студентам-психологам недостаточно достоверным и объективным либо противоречащим их знаниям. Более того, эксперимент демонстрировал подтасовку фактов, что, возможно, также негативно сказалось на оценке персонажа, поскольку этический кодекс исследователя предполагает честность, беспристрастность, незаинтересованность и прочие моральные качества, оцениваемые респондентами как крайне важные для ученого. Заведомый обман воспринимался респондентами как несоответствующий образу ученого в обеих группах.

В группе работающих респондентов к числу сюжетов, наиболее далеких от образа идеального ученого, попал также и сюжет из фильма «Вселенная 


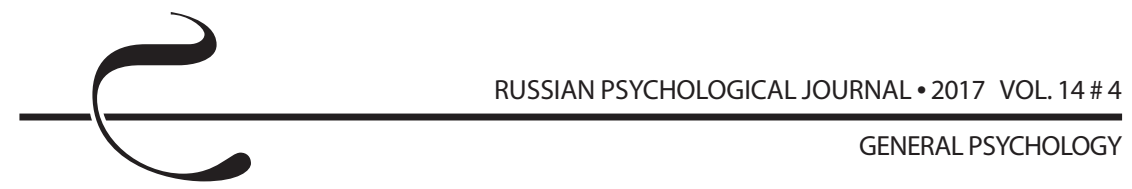

Стивена Хокинга». Возможно, это связано с тем, что выбранный отрывок демонстрировал нетипичную, с точки зрения респондентов, деятельность ученого - танцы и флирт на вечеринке. Научное содержание беседы, которая при этом происходит, по-видимому, игнорируется испытуемыми, является незначимым либо воспринимается как неуместное.

В работах ряда зарубежных авторов показано, что чем более стереотипным представляется образ ученого, тем с меньшей вероятностью молодежь выберет научную карьеру в качестве профессиональной [21, 22]. С этой позиции студенты имеют больше шансов перейти от учебной деятельности к научно-исследовательской, сделав ее своей основной профессией, а вероятность того, что работающая молодежь переориентируется на научно-исследовательскую работу, крайне незначительна. Поэтому профориентационные мероприятия в области научно-исследовательской деятельности, которые будут, в том числе, включать мероприятия по созданию адекватного образа современного научного работника, целесообразно начинать в старших классах школы и в вузе.

\section{Выводы}

По итогам исследования можно сказать, что образ ученого в группах студентов и работающей молодежи достаточно схож, но при этом упрощен и включает два основных фактора - когнитивный и личностный. Так, идеальный ученый должен обладать когнитивными характеристиками (целеустремленность, решительность, принципиальность, разносторонность, неординарность, высокая работоспособность, нацеленность на результат, воображение) и личностными качествами (терпимость к неопределенности, самодисциплина, способность правильно формулировать проблему), позволяющими быть продуктивным в исследовательском поиске. Причиной сходства имиджа является, в первую очередь, опыт высшего образования респондентов, в рамках которого они знакомятся с основами наук, ее историей, автобиографиями ученых. Однако этот опыт приводит к определенной стереотипизации имиджа, чему способствует унификация образовательных программ, сокращение общегуманитарного и естественнонаучного циклов.

Образ идеального ученого довольно близок к кинематографическим образам, но для первой группы студентов - это образы реальных ученых, и имиджформирующей основой выступает мыслительная исследовательская деятельность. Для работающей молодежи - это могут быть как образы реальных, так и вымышленных ученых, а имиджформирующей основой здесь является наличие внешних стереотипных представлений о работе ученого: инструментария и продукта. Это обусловлено сокращением притока новых общенаучных знаний и контакта с их носителями у работающих респондентов, 
недостаток которых восполняется за счет СМИ - в том числе Интернета, кинематографа. Таким образом, содержание деятельности - учебной и профессиональной - оказывает определенное влияние на имидж ученого через приоритетные источники его формирования. Отсутствие поступления адекватной и реалистичной информации о научных работниках в дальнейшем может приводить к усилению стереотипизации и искажению образа ученого в сознании молодежи.

\section{Литература}

1. Воробьева E. В. Технология объективной психофизиологической оценки мотивационных особенностей студентов-психологов. - М. : КРЕДО, 2016. - 102 c.

2. Ушаков Д. В. Культура и поддержка знания, интеллекта, одаренности // Социальная психология знания / под общ. ред. А. Л. Журавлева, Д. В. Ушакова. - М. : Изд-во ИП РАН, 2016. - С. 89-112.

3. Юревич А. В. Социально-психологические особенности российской науки // Социальная психология знания / под общ. ред. А. Л. Журавлева, Д. В. Ушакова. - М. : Изд-во ИП РАН, 2016. - С. 176-196.

4. Журавлев А. Л., Нестик Т. А. Социально-психологические методы фасилитации совместного анализа опыта и обмена знаниями // Социальная психология знания / под общ. ред. А. Л. Журавлева, Д. В. Ушакова. - М. : Изд-во ИП РАН, 2016. - С. 357-377.

5. Юревич А. В. Социально-психологические факторы производства и распространения технологических инноваций // Социальная психология знания / под общ. ред. А. Л. Журавлева, Д. В. Ушакова. - М. : Изд-во ИП PAH, 2016. - C. 378-397.

6. Leydesdorff L., Perevodchikov E., Uvarov A. Measuring Triple-Helix Synergy in the Russian Innovation Systems at Regional, Provincial and National Levels // Journal of the Association of Information Science and Technology. - 2015. Vol. 66, Issue 6. - P. 1229-1238. - DOI: 10.1002/asi.23258

7. Гаврилова Е. В., Ушаков Д. В. Личностное знание в структуре передачи научного опыта // Социальная психология знания / под общ. ред. А. Л. Журавлева, Д. В. Ушакова. - М. : Изд-во ИП РАН, 2016. - С. 141-152.

8. Abakumova I. V., Ermakov P. N., Fedotova O. D., Latun V. V. Plagiarism and anti-plagiarism in education and science // EDULEARN16 Proceedings 8th International Conference on Education and New Learning Technologies. Barcelona : IATED, 2016. - C. 4714-4719.

9. Arzenšek A., Košmrlj K., Širca N. T. Slovenian young researchers' motivation for knowledge transfer // Higher education. - 2014. - Vol. 68, № 2. - P. 185-206. DOI: $10.1007 / \mathrm{s} 10734-013-9702-0$ 
10. Imbert C., Muldoon R., Sprenger J., Zollman K. Introduction. The collective dimension of science // Synthese. - 2014. - Vol. 191, № 1. - P. 1-2. - DOI: 10.1007/s11229-013-0349-2

11. Vermeir K. Scientific research: Commodities or commons? // Science and education. - 2013. - Vol. 22, № 10. - P. 2485-2510. - DOI: 10.1007/s11191-012-9524-y

12. Перелыгина Е. Б., Савичева Н. А. Развитие имиджа и личностной устойчивости руководителя // Человеческий капитал. - 2015. - № 1 (73). C. 51-53.

13. Цветкова Н. А., Петрова Е. А., Горшкова В. В. Социально-психологические характеристики текущего, зеркального и желаемого имиджа преподавателя вуза // Ученые записки Российского государственного социального университета. - 2017. - Т. 16, № 1 (140). - С. 50-61.

14. Moliner $P$. Les representations sociales et les images // Les representations sociales. Theories, methodes et applications / G. L. Monaco, S. Delouvee, P. Rateau (eds.). - Louvain-la-Neuve : Editions De Boeck, 2016. - P. 420-430.

15. Moliner P. Psychologie sociale de l'image. - Grenoble : Presses universitaires de Grenoble, 2016. - 166 p.

16. Les representations sociales. Theories, methodes et applications / G. L. Monaco, S. Delouvee, P. Rateau (eds.). - Louvain-la-Neuve : Editions De Boeck, 2016. - 510 p.

17. Разина Т. В. Структурно-функциональная организация и генезис мотивации научной деятельности : дисс. ... д. психол. н. - Ярославль, 2016. $-612 \mathrm{c}$.

18. Kossowska M., Bar-Tal Y. Need for closure and heuristic information processing: The moderating role of the ability to achieve the need for closure // British Journal of Psychology. - 2013. - Vol. 104, №4. - P. 457-480. - DOI: 10.1111/bjop. 12001

19. Labe B. I. Need for cognitive closure among vocational technical student teachers in some Nigerian universities // International Journal of Vocational and Technical Education. - 2016. - Vol. 8 (3). - P. 20-24. - URL: http://www. academicjournals.org/journal/IJVTE/article-abstract/345EE3558786

20. Володарская Е. А., Разина Т. В. Источниковая база для изучения имиджа ученого // Человеческий капитал. - 2017. - № 2 (98). - С. 6-11.

21. Christidou V. Interest, attitudes and images related to science: Combining students' voices with the voices of school Science, teachers, and popular science // International Journal of Environmental \& Science Education. 2011. - Vol. 6, Issue 2. - P. 141-159.

22. Miele E. Using the Draw-a-Scientist Test for Inquiry and Evaluation // Journal of College Science Teaching. - 2014. - Vol. 43, № 4. - P. 36-40. - DOI: 10.2505/4/jcst14_043_04_36 


\section{References}

1. Vorob'eva E. V. Tekhnologiya ob"ektivnoi psikhofiziologicheskoi otsenki motivatsionnykh osobennostei studentov-psikhologov [Method for objective psychophysiological assessment of psychology students' motivation]. Moscow, KREDO Publ., 2016. 102 p.

2. Ushakov D. V. Culture and supporting knowledge, intellect, and talent. In: Zhuravleva A. L., Ushakov D. V. (eds.) Sotsial'naya psikhologiya znaniya [Social psychology of knowledge]. Moscow, Institute of Psychology, Russian Academy of Science Publ., 2016, pp. 89-112.

3. Yurevich A. V. Socio-psychological characteristics of Russian science. In: Zhuravleva A. L., Ushakov D. V. (eds.) Sotsial'naya psikhologiya znaniya [Social psychology of knowledge]. Moscow, Institute of Psychology, Russian Academy of Science Publ., 2016, pp. 176-196.

4. Zhuravlev A. L., Nestik T. A. Socio-psychological methods for facilitating the joint analysis of experience and knowledge sharing. In: Zhuravleva A. L., Ushakov D. V. (eds.) Sotsial'naya psikhologiya znaniya [Social psychology of knowledge]. Moscow, Institute of Psychology, Russian Academy of Science Publ., 2016, pp. 357-377.

5. Yurevich A. V. Socio-psychological factors for producing and distributing technological innovation. In: Zhuravleva A. L., Ushakov D. V. (eds.) Sotsial'naya psikhologiya znaniya [Social psychology of knowledge]. Moscow, Institute of Psychology, Russian Academy of Science Publ., 2016, pp. 378-397.

6. Leydesdorff L., Perevodchikov E., Uvarov A. Measuring triple-helix synergy in the Russian innovation systems at regional, provincial and national levels. Journal of the Association of Information Science and Technology, 2015, V. 66, Issue 6, pp. 1229-1238. DOI: 10.1002/asi.23258

7. Gavrilova E. V., Ushakov D. V. Personal knowledge in transferring scientific experience. In: Zhuravleva A. L., Ushakov D. V. (eds.) Sotsial'naya psikhologiya znaniya [Social psychology of knowledge]. Moscow, Institute of Psychology, Russian Academy of Science Publ., 2016, pp. 141-152.

8. Abakumova I. V., Ermakov P. N., Fedotova O. D., Latun V. V. Plagiarism and anti-plagiarism in education and science. EDULEARN16 Proceedings 8th International Conference on Education and New Learning Technologies. Barcelona, IATED, 2016, pp. 4714-4719.

9. Arzenšek A., Košmrlj K., Širca N. T. Slovenian young researchers' motivation for knowledge transfer. Higher education, 2014, V. 68, no. 2, pp. 185-206. DOI: $10.1007 / \mathrm{s} 10734-013-9702-0$

10. Imbert C., Muldoon R., Sprenger J., Zollman K. Introduction. The collective dimension of science. Synthese, 2014, V. 191, no. 1, pp. 1-2. DOI: 10.1007/ s11229-013-0349-2 
11. Vermeir K. Scientific research: Commodities or commons? Science and education, 2013, V. 22, no. 10, pp. 2485-2510. DOI: 10.1007/s11191-012-9524-y

12. Perelygina E. B., Savicheva N. A. A manager's image and personal resistance. Chelovecheskii kapital - Human Capital, 2015, no. 1 (73), pp. 51-53 (in Russian).

13. Tsvetkova N. A., Petrova E. A., Gorshkova V. V. Socio-psychological characteristics of a university teacher's current, mirror, and desired image. Uchenye zapiski Rossiiskogo gosudarstvennogo sotsial'nogo universiteta-Scientific Notes of Russian State Social University, 2017, V. 16, no. 1 (140), pp. 50-61 (in Russian).

14. Moliner P. Les representations sociales et les images. In: Monaco G. L., Delouvee S., Rateau P. (eds.) Les representations sociales. Theories, methodes et applications. Louvain-la-Neuve, Editions De Boeck, 2016, pp. 420-430.

15. Moliner P. Psychologie sociale de l'image. Grenoble, Presses universitaires de Grenoble, 2016. 166 p.

16. Monaco G. L., Delouvee S., Rateau P. (eds.) Les representations sociales. Theories, methodes et applications. Louvain-la-Neuve, Editions De Boeck, 2016. 510 p.

17. Razina T. V. Strukturno-funktsional'naya organizatsiya i genezis motivatsii nauchnoi deyatel'nosti [Structural functional organization and genesis of motivation for scientific activity]. Diss. Dr. Sci. (Psych.). Yaroslavl, 2016.612 p.

18. Kossowska M., Bar-Tal Y. Need for closure and heuristic information processing: The moderating role of the ability to achieve the need for closure. British Journal of Psychology, 2013, V. 104, no. 4, pp. 457-480, DOI: 10.1111/bjop.12001

19. Labe B. I. Need for cognitive closure among vocational technical student teachers in some Nigerian universities. International Journal of Vocational and Technical Education, 2016, V. 8 (3), pp. 20-24. URL: http://www.academicjournals.org/journal/IJVTE/article-abstract/345EE3558786

20. Volodarskaya E. A., Razina T. V. Source base for studying the scientist's image. Chelovecheskii capital, 2017, no. 2 (98), pp. 6-11.

21. Christidou V. Interest, attitudes and images related to science: Combining students' voices with the voices of school Science, teachers, and popular science. International Journal of Environmental \& Science Education, 2011, V. 6, Issue 2, pp. 141-159.

22. Miele E. Using the Draw-a-Scientist Test for inquiry and evaluation. Journal of College Science Teaching, 2014, V. 43, no. 4, pp. 36-40. DOI: 10.2505/4/ jcst14_043_04_36 